\title{
非静的環境における不完全地図を用いたロボットによる 自己位置推定法*
}

\author{
田 中 完 爾*1, 岡 田 伸 廣*1 \\ 長谷川勉 ${ }^{* 2}$, 近 藤 英 二*1

\section{Mobile Robot Localization with an Incomplete Map in Non-Stationary Environments}

\author{
Kanji TANAKA*3, Nobuhiro OKADA, \\ Tsutomu HASEGAWA and Eiji KONDO \\ ${ }^{* 3}$ Graduate School of Engineering, Kyushu University, \\ 6-10-1 Hakozaki, Higashi-ku, Fukuoka-shi, Fukuoka, 812-8581 Japan
}

\begin{abstract}
One of the fundamental problems of the mobile robots is self-localization, i.e. to estimate the self-position by comparing sensor data and a map. In non-stationary enviroments, a robot should avoid to use changed objects as landmarks in the localization. In this paper, we propose a selflocalization method that is robust against changes in environments. The method identifies changes from noisy and ambiguous sensor data. Since an object with a random shape may be added at a random position, it genetates and utilizes multiple hypotheses about the changes. A number of simulation experiments have been performed in various environments, to demonstrate the effectiveness of the method.
\end{abstract}

Key Words: Mobile Robot, Self-localizaqtion, Change Detection

\section{1.はじめに}

ロボットが様々なタスクを実行する上で, 環境内に おける自己位置を知ることは重要である. 環境内の物 体配置を記した地図とセンサデータを照合することに よって, 自己位置を推定する問題について, 様々な研究 が行われてきた (2) (5)(7)(9). Thrun らによると, 自己位 置推定問題には難しさの異なるいくつかのカテゴリが 存在する ${ }^{(9)}$. 環境が静的であり, 自己位置が予めある程 度分かっている場合には, 比較的簡単なモデルを当て はめることができ, カルマンフィルタなどの方法を用 いて自己位置が求まる ${ }^{(3)}$.これに対し, 自己位置が完全 に未知である場合や, 環境が非静的である場合には, い くつかの未解決な課題がある.

自己位置が完全に未知である場合, 地図中の全ての 局所領域をセンサデータと照合しなければならない. 類似した場所の存在により,しばしば自己位置を一意 に決定することが出来ず, 複数の仮説を生成しなけれ ばならない. 誤った仮説を棄却するためには, 移動を絽 りかえしながら多数の地点でセンサデータを取得する 必要がある. 自己位置の曖昧さを扱うために, 確率的な 推定方法に注目が集まっている( ${ }^{(10)}$.

* 原稿受付 2003 年 4 月 15 日.

*1 正員, 九州大学大学院工学研究院 ( 812-8581 福岡市東区 箱崎 6-10-1).

*2 九州大学大学院システム情報科学研究院.

E-mail : kanji@mech.kyushu-u.ac.jp
物体配置変化のある非静的な環境では, 地図が誤っ たものになる可能性がある.このため, 地図とセンサ データを単純に照合することは, 必ずしも正しい自己 位置を得ることにつながらない.このような環境では， 物体配置についても複数の仮説を生成すべきであると 考えられる.ただし,物体配置に関する仮説は無数に存 在し,その数を制約するため, 何らかのヒューリスティ クスを導入する必要がある.

本論文は, 非静的環境における自己位置推定を対象 とする. ただし,センサデータとして,一地点で取得し た 2 次元の全方位距離データを用いる. また, 移動物体 は存在しないものと仮定する.

非静的環境では, 複数の物体が相互の位置関係を保つ たまま動くことは稀である,という性質を利用するこ とが有効である ${ }^{(6)}$.すなわち, センサデータと地図を見 比べて, 位置関係が合致する物体群が見つかったなら ば, それらの物体の配置は変化していない可能性が高 い.この考えは, 投票法 ${ }^{(7)} に よ り$ 実現できる.すなわち， 各センサデータについて, それが地図と合致する自己 位置に投票し, 得票数の多かった自己位置ほど正しい とみなす. 以下,この方法を SM(Simple Matching) 法と 呼ぶ.

SM 法は, 多数決に基づいているため, 物体配置変化 の割合が小さい場合には有効であるが, 大きい場合に 


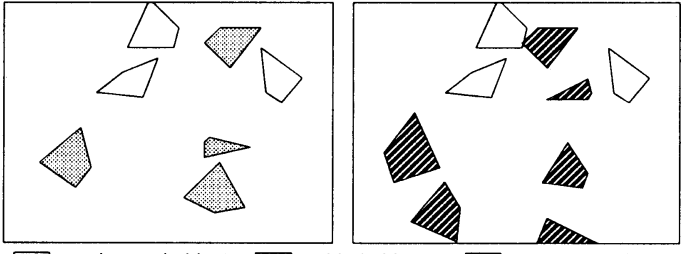

: unchanged object $\mathbb{Z} / \mathrm{t}$ : added object

(a)

(b)

Fig. 1 (a) Map. (b) Modified environment. There are 4 removed objects, and 6 added objects in the environment.

は対処できないと予想される.そこで,物体配置変化を 見分けるための工夫が必要となる.一つのアプローチ として, 本研究では, 観測された物体の位置と形状をも とに,その物体が地図に記されたものと同一であるか どうかを判断することにした ${ }^{(8)}$.このようなアプロー チはコンピュータビジョンの物体認識において用いら れるが, さらに本問題では, 自己位置や物体観測におけ る曖昧さのために, 多数の仮説を立てる必要がある. 本 論文では，こうした多数の仮説に基づいた物体配置変 化の検出を行うことにより, 非静的環境において自己 位置を推定する方法を提案する. また, 物体の密度と出 現頻度の条件を変化させながら, 各条件について 1000 通り程度の環境を計算機内に構築し, シミュレーショ ンにより提案法と SM 法を比較した.この結果をもと に, 物体配置変化に対する本方法の有効性と限界を検 証する.

\section{2. 問 題 設 定}

$2 \cdot 1$ 物体配置の変化物体配置の変化は,2 種類 に分類することができる. 1 つは, 地図に記されていな い物体の出現であり,これを物体出現と呼ぶ.もう1つ は, 地図に記されていた物体の消失であり,物体消失と 呼ぶ.ただし, 環境内における物体の移動は, ある地点 における物体消失と, 別の地点における物体出現の組 み合わせであるとして扱う。図 1 に物体配置変化の例 を示す.

2.2 センサデータ センサデータとして, 2 次元 の全方位距離データが与えられているものとする.こ のようなデータは, 全方位ビジョンセンサ ${ }^{(1)}$ などによ り得ることができ, 移動ロボットのナビゲーションな どによく利用される. 各データは, 各方位にある最も近 い物体までの距離を測定したものであり, ランダムな センサノイズ $\Delta d \in\left[\Delta d_{a}-\Delta d_{b}, \Delta d_{a}+\Delta d_{b}\right]$ が乗るもの

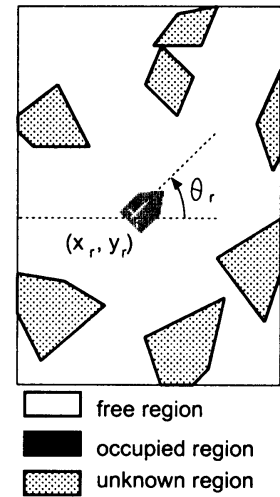

(a)

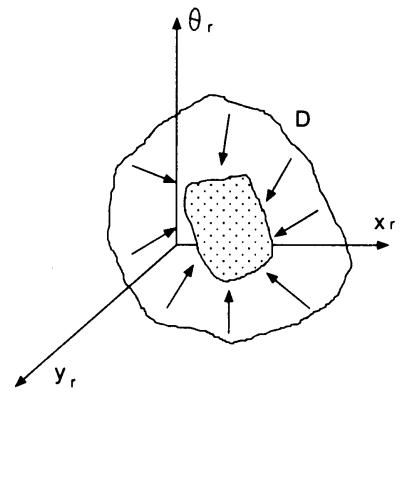

(b)
Fig. 2 Purpose of the localization. (a) Definition of the robot position. (b) Refining the robot position to more localized region.

とする. ただし, $\Delta d_{a}, \Delta d_{b}$ は, ある一定值である.

2.3 地図 床面上の 2 次元領域をセルに分割し, 各セルが障害物により占有されているかどうかの状態 を記録した地図を利用する. 各セルは, 一辺 $10 \mathrm{~cm}$ の正 方形領域を指す. 占有状態は, 以下のいずれかの值をと る. UNKNOWN : 占有状態が未知である, OCCUPIED : 占有されている, FREE : 占有されていない.

2.4 自己位置推定の目的 自己位置推定の目的 は, センサデータと地図を用いて, 自己位置 $\left(x_{r}, y_{r}, \theta_{r}\right)$ をできるだけ狭い範囲に限定することである.ただし， $\left(x_{r}, y_{r}\right)$ と $\theta_{r}$ は, 各々, ロボットの位置と姿勢を表し, 図 2 に示すように, 自己位置のとりうる範囲は, 3 次元領 域 $D$ により表される.

自己位置推定は, 以下に示す 3 つのステージにより 実行される。

1. 空間的に連続したデータ点をクラスタリングする ことにより,物体を抽出する.

2. 抽出された物体を地図と比較することにより, 明 らかに変化である物体を検出する.

3. 残りの物体の”変化らしさ”を評価し, 変化らしさ の低い物体を地図と照合することによって, 自己 位置を推定する.

\section{3. センサデータ処理}

3.1 物体の抽出 センサデータから物体を抽出 する方法としては,様々なものが考えられるが, 本研究 では, 環境内にある物体が凸形状であることを仮定し， 以下の簡単な方法を用いた. まず, 全方位距離データを 


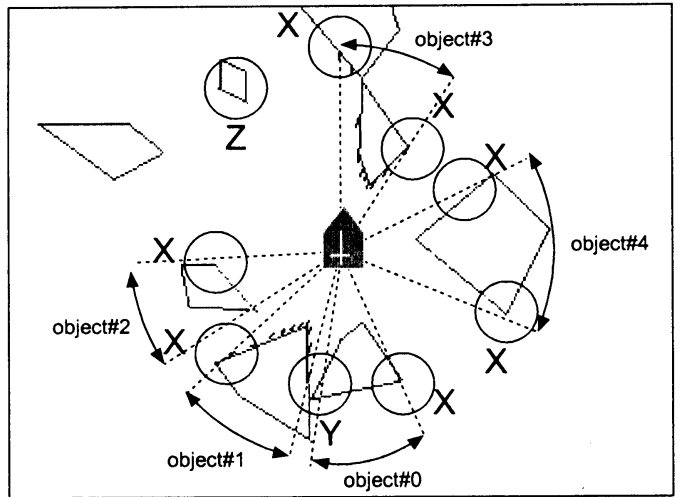

Fig. 3 Extracting objects by searching object boundaries in the sensor data. As a result, 5 objects are extracted. ' $\mathrm{X}$ ','Y','Z' indicate different types of boundaries.

反時計周りに走査しながら, 物体の境界に属するデー タを見つけ,データを物体毎にクラスタリングする. 2 点以上のデータ点を含むクラスタを, 物体に対応する とみなし, センサ物体と呼ぶ. センサ物体の集合を $S$ と 表す. 図 3 で, クラスタ'Z'は,ただ 1 つのデータ点し か含まないため,センサ物体とはみなされない

物体の境界には 2 種類ある.一つは, 孤立した物体の 境界であり, あるデータと次のデータとの差が, 闒值 $T_{1}$ よりも大きいならば, そのデータは境界に属するとみ なす (図 3 中のタイプ'X'の境界).もう一つは, 隙間な

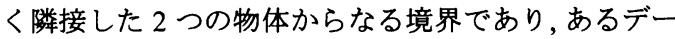
タが, 両隣りのデータよりも $T_{2}\left(<T_{1}\right)$ 以上大きいなら ば,そのデータは境界に属するとみなす (図 3 中のタイ プ'Y'の境界).

3.2 明らかな変化の検出 もし,どのような自己 位置 $p(\in D)$ を仮定しても, あるセンサ物体が地図中の 物体と合致しえないならば, そのセンサ物体は明らか に物体出現である.このような物体は, 自己位置の推 定に用いるべきではないので, 検出し,Sから除外して おく.

あるセンサ物体と地図中のある物体が合致するか どうかの判定では, そのセンサ物体に含まれるデー タと地図を比較する. すなわち, 各データの許容範囲 $\left[d+\Delta d_{a}-\Delta d_{b}, d+\Delta d_{a}+\Delta d_{b}\right]$ の中に, 少なくとも 1 つ の OCCUPIED セルがあるならば, そのセンサ物体は 地図と合致するものとみなす。

3.3 変化らしさの推定変化である可能性が低 いセンサ物体ほど, 自己位置推定に適している. 本節で

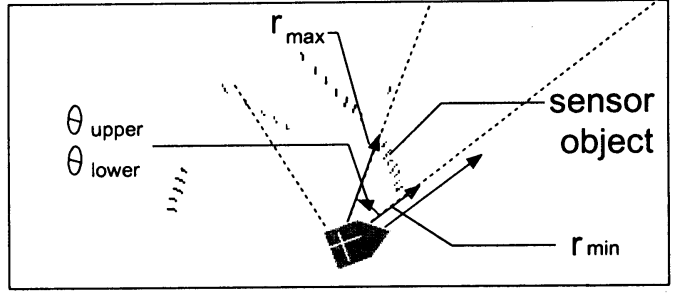

(a)

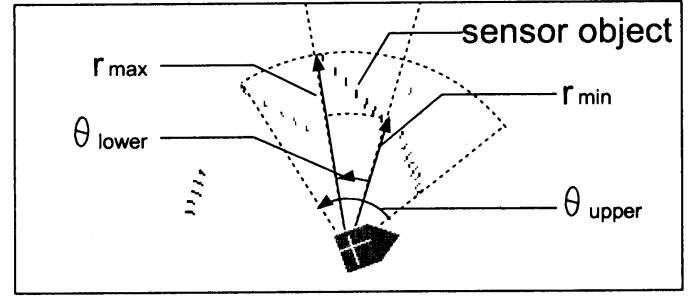

(b)

Fig. 4 Estimating parameters of sensor objects, as well as their likelihood of change. A short line segment represents a sensor data point. (a) Sensor object not occluded. (b) Sensor object partially occluded.

は, 自己位置やセンサデータの不確かさを考虑しなが ら, あるセンサ物体 $s(\in S)$ の”変化らしさ”を評価する 方法について述べる. もし変化らしさが, ある闒值 $T_{3}$ よりも小さければ, そのセンサ物体を自己位置推定に 用いることができるものとみなす。

いま,物体が出現する位置と形状が，一様な分布に従 うと仮定する. 出現物体がとりうる全ての位置および 形状のうち, センサ物体 $s$ と合致するものの数を, それ ぞれ $U_{p}(s), U_{s}(s)$ と表す.このとき

$$
U(s)=U_{p}(s) U_{s}(s)
$$

は, 観測されたそのセンサ物体が出現物体である事後 確率に比例する. この $U(s)$ を変化らしさと呼ぶ.

自己位置と距離データの不確かさにより, センサ物 体の位置には曖昧さがある. $U_{p}(s)$ は, この曖昧さの大 きさとなる. 通常, 自己位置の不確かさに比べて, 距離 データの不確かさは無視できるほど小さい. そこで, $U_{p}(s)$ を自己位置の不確かさにより近似する.すなわ ち, 自己位置のとりうる範囲 $D$ の体積を $U_{p}(s)$ とする. 同様に, センサ物体の形状をパラメータにより表し たとき, パラメータの曖昧さが $U_{s}(s)$ となる. ただし, 複雑なパラメータ表現を用いると, $U_{s}(s)$ を求める処理 が複雑になり, ロボットのアプリケーションには適さ ない. ここでは, 物体の幅 $a$ および奥行き $b$ という, 2 
つのパラメータのみによる簡単な表現を用いることに した.

出現しうる物体の候補からなる集合

$$
O=\{(a, b)\}
$$

を導入し,センサ物体 $s$ と形状が合致する要素 $(a, b) \in O$ の数を, $U_{s}(s)$ とする. センサ物体 $s$ を幅 $w$ と奥行 き $d$ により表し, $w, d$ の許容範囲を, [ $\left.w_{\text {lower }}, w_{\text {upper }}\right]$, $\left[d_{\text {lower }}, d_{\text {upper }}\right]$ と表す. そして, センサ物体 $s$ と物体 $(a, b)$ の形状が一致するかどうかを,

$$
\left(a \in\left[w_{\text {lower }}, w_{\text {upper }}\right]\right) \wedge\left(b \in\left[d_{\text {lower }}, d_{\text {upper }}\right]\right)
$$

により判定する. ただし, センサ物体の見込角を $\theta$ と したとき,

$$
w \simeq\left\{\left(r_{\text {min }}+r_{\text {max }}\right) / 2\right\} \theta
$$

が近似的に成り立つものとし， $\theta$ の許容範囲 $\left[\theta_{\text {lower }}, \theta_{\text {upper }}\right]$ を求めることによって, $\left[w_{\text {upper }}, w_{\text {lower }}\right]$ を得る. 図 4 に, 各パラメータを図示する.

物体 $s$ の背面は, その物体自身によって隠されている ので, $d_{\text {upper }}$ は, 常に無限大である. $d_{\text {lower }}$ は $\left(r_{\text {max }}-r_{\text {min }}\right)$ となる.

センサ物体 $s$ 中のデータ点を

$$
\left\{p_{i}, p_{i+1}, \cdots, p_{j}\right\}
$$

と表すとき, $p_{i}$ と $p_{j}$ の間の見込角が, $\theta_{\text {lower }}$ となる. $\theta_{\text {upper }}$ は, 以下の手順により求める.

1. もし $p_{i}$ か $p_{j}$ のいずれかが測定範囲外であれば, $\theta_{\text {upper }}=\infty$ として終了する.

2. $p_{i}$ と $p_{j}$ の間の見込角を $\theta_{\text {upper }}$ とする.

3. もし距離が $r_{\text {max }}$ よりも小さいデータ点 $\left\{p_{i^{\prime}}, \cdots\right.$, $\left.p_{i-1}\right\}$ があれば,それらが物体 $s$ を部分的に隠して いると判断する.そこで, $p_{i^{\prime}}$ と $p_{j}$ の間の見込角を $\theta_{\text {upper }}$ に加える.

4. 同様に, もし距離が $r_{\text {max }}$ よりも小さいデータ点 $\left\{p_{j+1}, \cdots, p_{j^{\prime}}\right\}$ があれば, $p_{i}$ と $p_{j^{\prime}}$ の間の見込角 を $\theta_{\text {upper }}$ に加える.

\section{4. 自己位置推定}

$4 \cdot 1$ 投粟法による推定 自己位置の不確かさ $U_{p}(s)$ は, しばしば非常に大きく, 3 節の方法によって も変化を識別することができないことがある.このよ うな場合, 物体相互の位置関係を利用することは有効 である ${ }^{(6)}$. すなわち, あるセンサ物体群 $H(\subset S)$ の位置 関係と, 地図中のある物体群の位置関係とが合致すれ ば, それらの物体群の配置は変化していない可能性が 高い.
この考えに基づき, 投票法により自己位㯰を絞りこ む方法を示す.ここでは, センサ物体群 $S$ の任意の部 分集合 $H(\subset S)$ を生成し,

- $H$ 中の物体の配置が変化していない

という仮説が, 全ての $H$ について同等に確からしいと みなして投票を行う。すなわち, 各 $H$ について, $H$ 中の 全センサ物体が地図と合致するような自己位置の範囲 を求め, その範囲内の各位置に一票ずつ投票する. その 結果, 得票数が多い位置ほど, 正しい自己位置である可 能性が高いとみなす。

4.2 検証 この投票には, 本来, 物体配置変化に 属さないセンサ物体だけを用いるべきである. そこで, 最新の推定結果 $D_{H}$ をもとに, $S$ 中の各センサ物体が 物体配置変化に属するかどうかを検証し, 属するとみ なされたならば $S$ から除外する.

ここでは, $S$ 中のあるセンサ物体 $s$ を残りの $S-\{s\}$ を用いて検証するという方法をとる. すなわち, $S-\{s\}$ の全ての部分集合 $H^{\prime}(\subset S-\{s\})$ を生成し, 各センサ物 体群 $H^{\prime}$ が変化していないという仮定の下で, $s$ を検証 する. まず, $H^{\prime}$ 中の全ての物体が地図と合致するよう な自己位置の範囲 $D_{H^{\prime}}$ を求め, $D$ の代わりに $D_{H^{\prime}}$ を用 いて不確かさ $U(s)$ を求め, $U(s)<T_{3}$ であるかどうか を判定する. 全てのセンサ物体についての判定が完了 した後で,一度も判定条件を満たさなかったセンサ物 体 $s$ を信頼度が低いものとみなして $S$ から除外する.

ここで, 全ての $D_{H^{\prime}}$ を算出しようとすれば膨大な計 算時間がかかるが, 各センサ物体 $s$ が地図と合致する 自己位置範囲 $D_{s}$ が既に求まっていることを利用する と, 各 $D_{H^{\prime}}$ は, いくつかの $D_{s}$ の積集合として求められ る. すなわち, 予め $D_{s}$ の参照テーブルを作成しておく ことによって, 計算量の増加は殆どない.

もし, 除外すべきセンサ物体が, 1 つでも見つかった ならば, 誤った前堤をもとに, 自己位置を推定していた ことになる. そこで, 更新された $S$ を用いて, 4.1 節の 推定処理を, 始めからやり直す.なお, 推定処理におい て, 最も計算量を要するのは投票の部分であるが, 再推 定では前回の投票結果を利用できるので, 再投票を行 う必要はない.

以上の検証の結果, $S$ 中からセンサ物体が 1 つもなく なり, 投票が行えなくなることがある. その場合, セン サデータの不確かさが大きすぎたものと考え, ロボッ 卜位置の推定 $D$ は更新しない.

$$
\text { 5. シミュレーション }
$$

環境やロボットを計算機内に構築し, 数多くの環境 と物体配置変化に対して, 自己位置推定のシミュレー 

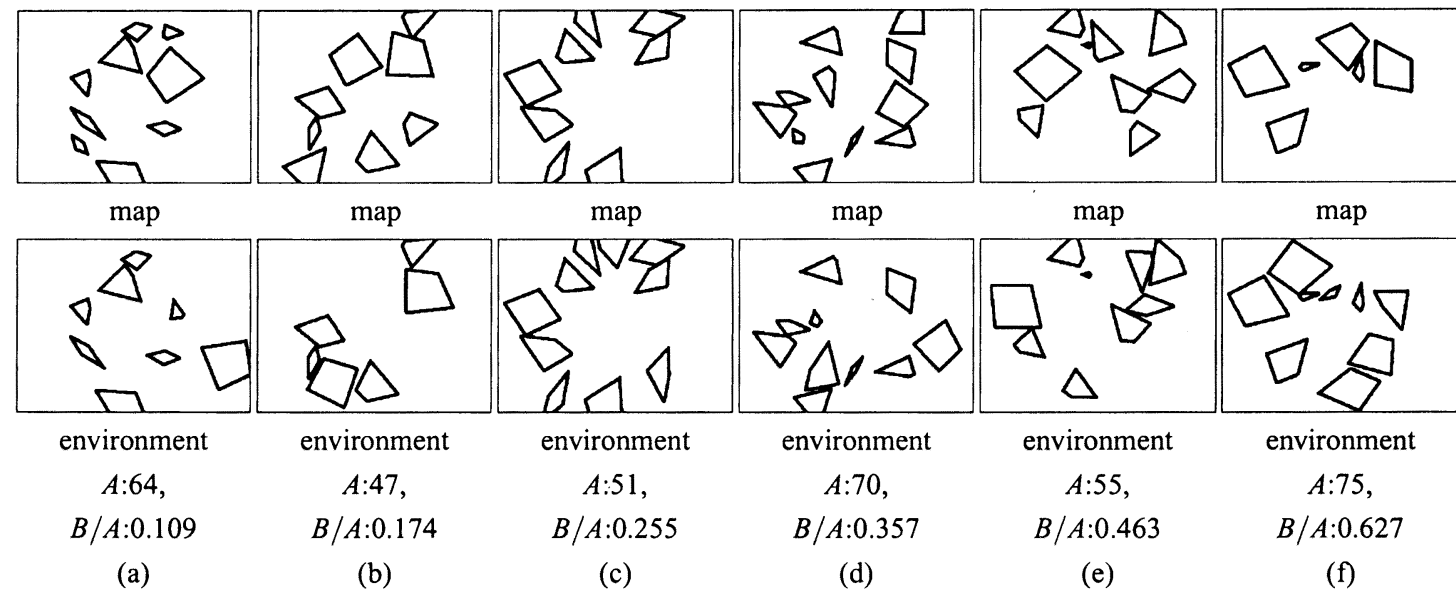

Fig. 5 Some examples of initial map and environment in the experiment. $A$ is the number of sensor data points, while $B / A$ represents the rate of changes.

ションを行った. 図 5 に, 実験で用いた地図と環境の例 を示す.

$5 \cdot 1$ 設定 パラメータは, $T_{1}=50[\mathrm{~cm}], T_{2}=$ $25[\mathrm{~cm}], T_{3}=4.5 \times 10^{5}\left[\mathrm{~cm}^{2} \cdot \mathrm{deg}\right]$ と与えた. ロボット 位置 $\left(x_{r}, y_{r}\right)$ の初期推定を半径 $1[m]$ の円とし, $\theta_{r}$ の初 期推定を範囲 $[-10,10][\mathrm{deg}]$ とした. ロボット上には, 全方位距離センサが搭載されており, 距離 $3[\mathrm{~m}]$ 以内の 最も近い物体までの距離を, 100 方向について取得する. 本研究室で使用している距離センサの特性をもとに, $\Delta d_{a}=0[\mathrm{~cm}], \Delta d_{b}=5[\mathrm{~cm}]$ と与えた. $O=\{(a, b) \mid a, b \in$ $[10,300]\}$ とした. 地図の解像度は $9[\mathrm{~cm}] \times 9[\mathrm{~cm}]$ とし, 環境のサイズは 9.6 $[\mathrm{m}] \times 7.2[\mathrm{~m}]$ とした. 投票用の 3 次 元配列の解像度は, $9[\mathrm{~cm}] \times 9[\mathrm{~cm}] \times 9[\mathrm{deg}]$ とした.

シミュレーションでは, 1000 通り以上の多様な地図 と環境の組を, 以下の手順により自動生成した. (1) ラ ンダムな個数の物体を, ランダムな場所に置くことに よって, 地図を生成する.ただし, その際, 物体同士が 重なり合わないようにする. 物体は四角形であるとし, その頂点はランダムな位置に選んだ. 物体の縦横の幅 が, $3[m]$ 以内に収まるようにした. (2) 物体を地図中に 加えたり, 既に地図中にある物体を動かしたりして, 環 境を生成した. 物体を動かす際, いくつの物体を動かす かをランダムに決め, その個数 $n$ だけ, 物体をランダム な位置に動かした.ただし，その際，物体同士が重なり 合わないようにした.

提案法との比較のために, Simple Matching (SM) 法 と呼ぶ方法の結果も示す. SM 法は, 提案法と同様に, 投票により自己位置を推定するが，その投票の条件が 異なる. 提案法では, 信頼度の高いと評価された各セン
サ物体が地図と合致する自己位置へ,一票ずつ投票し ていた.これに対し, SM 法では, 各データ点が地図と 合致する自己位置へ投票する.

各環境における自己位置推定の難しさを計るための 指標として,以下の 2 つを用いる.

$A$ : いずれかの物体から返ってきたセンサデータの数

$B$ : 出現した物体から返ってきたセンサデータの数 $A$ が大きい程, センサデータ間の相互の関係を利用し て, ロボット位置を正確に推定しやすくなる. $B$ が大き い程, 哭認識の可能性が高くなる.この指標にしたが い, 全ての環境を難しさにより分類した. まず, 変化の 割合を表す $B / A$ をもとに, $B / A$ が $0.0-0.3,0.3-0.6$, $0.6-0.75$ の 3 つのグループに分類した. この各グルー

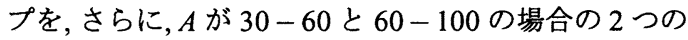
グループに分けて, 計 6 つのグループを得た. 各グルー プには, 地図と環境の組が 500 ずつ含まれている.

自己位置推定の達成度を計る一つの方法として, 自 己位置の推定值と真值のユークリッド距離を調べるこ とが挙げられる.しかし,この評価法は, 観測後に推定 自己位置の事後確率分布が単峰性 (e.g. ガウス分布) と なり, その分布のピーク近傍に自己位置の期待值があ ることを前堤としている. 一方, 近年 Thrun ${ }^{\left({ }^{9}\right)}$ らが指摘 しているように, 単一地点において観測後の事後分布 は, 単峰性とならないことが多い.

これに代わる評価尺度として, 不確かさを

- 真の自己位置以上の得票数を得た位置侯補の数 と定義し,これを用いて自己位置推定の達成度を表す. この尺度により, 自己位置分布の形状によらず, 達成度 を計ることができる。 


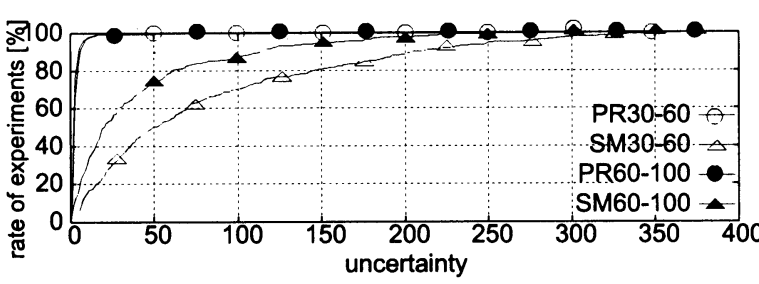

(a)

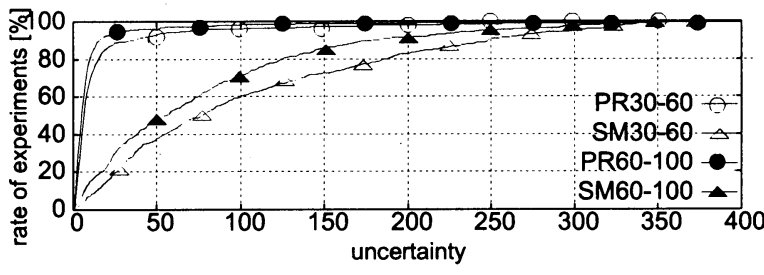

(b)

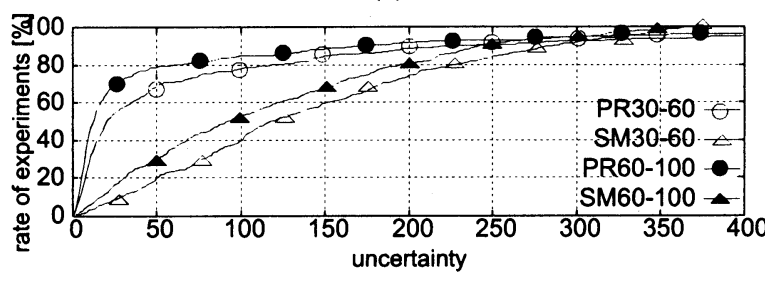

(c)

Fig. 6 Results of experiments. 'PR' and 'SM' indicate the results of proposed method and simple matching method, respectively. Each figure shows the results for $A$ is in $30-60$ and $60-$ 100. (a) $B / A: 0-30 \%$. (b) $B / A: 30-60 \%$. (c) $B / A: 60-75 \%$.

5.2 結果と考察 図 6 に, 実験結果を示す. 図中 で, “uncertainty” は, 不確かさの評価值を表す. 縦軸の 值 “rate of experiments” は, 各 “uncertainty” 值に対応 する実験結果の割合 [\%] である. ただし, $4 \cdot 2$ 節で述べ たように, 提案法は, センサデータの不確かさが大き すぎると判断したときロボット位置の推定 $D$ を更新 しない. そのような結果は, このグラフには反映しな かった.

これらの結果より,以下のことが分かる. (1) 両方法 とも, $B / A<0.3$ の場合は, 比較的正確な結果を得るこ とができる. (2) 提案法だけが, $B / A<0.6$ の場合に, 殆 ど正確な結果を得ることができる. (3) $B / A>0.6$ であ るとき, 両方法ともロボット位直を正確に推定できて いない. SM 法に比べて提案法が良い結果を示した理 由は, 投票条件の違いにある. SM 法では全てのセンサ データの信頼度が等しいものと仮定して投票を行って
いるため, センサノイズや物体配置変化による不確か さに影響されやすい.これに対し, 提案法は, 物体配置 変化に属さない可能性が高いセンサデータのみを用い て投票を行っているため, 外乱による影響を受けにく かったと考えられる.

本手法では, 環境内の物体を凸物体と仮定している. したがって, 凹物体や, より複雑な形状をもつ物体の割 合が多い環境では, 提案法がうまく機能しない可能性 がある. 主に, 以下のような問題が挙げられる. (1) 凹 物体を幅と奥行により近似してしまうことにより,大 きなモデル化誤差が生じ, 不確かさ $U(s)$ を正確に評価 することができない. (2) 1 つの凹物体を,2 つ以上のセ ンサ物体として認識してしまう. 4.1 節の処理では, 各 センサ物体につき一票の投票権があるため, 凹物体が 不当に多くの投票権を得てしまうことになる.これら の問題に対処するため, センサ物体の抽出法, パラメー 夕表現法について,さらなる検討が必要である.

\section{6. むすび}

本論文では, 非静的環境における自己位置推定法を 提案した. 提案法は, 自己位膡と物体配直変化につい て複数の仮説を生成し，それらが同等に確からしいと みなした上で, 投票方式によって自己位置を決定する。 物体配固変化の位置や形状についての制約を極力設け ていないため,様々な㻴境に適用することができる. シ ミュレーションにより,多様な環境と変化の下で提案 法の有効性が示された.

\section{文献}

(1) R. Bunschoten and B. Kröse: “ Robust scene reconstruction from an omnidirectional vision system", Tech. Rep. IAS-UVA-02-02, Univ. of Amsterdam, 2002.

(2) J. Castellanos, J. Martinez, J. Neira and J. Tardós: "Simultaneous Map Building and Localization for Mobile Robots: A Multisensor Fusion Approach", Proc. IEEE Int. Conf. Robotics and Automation, pp.1244-1249, 1998.

(3) G. Dissanayake, H. Durrant-Whyte and T. Bailey: "A Computationally Efficient Solution to the Simultaneous Localization and Map Building (SLAM) Problem", Proc. IEEE/RSJ Int. Conf. Robotics and Automation, pp. 1009-1014, 2000.

(4) J. Gutmann, W. Burgard, D. Fox and K. Konolige: "An Experimental Comparison of Localization 
Methods", Proc. IEEE/RSJ Int. Conf. Intelligent Robots and Systems, pp.736-743, 1998.

(5) A. Howard, M. J. Mataric and G. Sukhatme: "Relaxation on a Mesh: a Formalism for Generalized Localization", Proc. IEEE/RSJ Int. Conf. Intelligent Robots and Systems, 2001.

(6) G. Magin, A. Ruß, D. Burschka and G. Färber: “A Dynamic 3D Environmental Model with RealTime Access Functions for Use in Autonomous Mobile Robots", J. Robotics and Autonomous Systems, vol.14, pp.119-131, 1995.

(7) M. Restelli, D. G. Sorrenti, F. M. Marchese: "A robot localization method based on Evidence Accumulation and Multi-Resolution", Proc. IEEE/RSJ Int. Conf. Intelligent Robots and Systems, pp. 415-420, 2002.

(8) K. Tanaka, T. Hasegawa, H. Zha, E. Kondo and N. Okada: "Mobile Robot Localization with an Incomplete Map in Non-Stationary Environments", IEEE Proc. Robotics and Automation (ICRA), 2003.

(9) S.Thrun, D.Fox, W.Burgard and F.Dellaert: "Robust Monte Carlo Localization for Mobile Robots", Artificial Intelligence Journal, 2001.

(10) S. Thrun: "Robotic Mapping: A Survey", CMUCS-02-111, 2002. 